\title{
Improving trends in survival of patients who receive chemotherapy for metastatic or recurrent gastric cancer: 12 years of experience at a single institution
}

\author{
Dong Hoe Koo $\cdot$ Min-Hee Ryu $\cdot$ Baek-Yeol Ryoo $\cdot$ Jinjoo Seo $\cdot$ Mi-Yeon Lee $\cdot$ \\ Heung-Moon Chang • Jae-Lyun Lee $\cdot$ Sung-Sook Lee $\cdot$ Tae Won Kim • \\ Yoon-Koo Kang
}

Received: 9 January 2014/Accepted: 23 April 2014/Published online: 16 May 2014

(c) The International Gastric Cancer Association and The Japanese Gastric Cancer Association 2014

\begin{abstract}
Background The aim of this retrospective study was to evaluate the changes in clinical features and treatment outcomes of the patients with metastatic or recurrent gastric cancer (MRGC) treated in the past 12 years.

Methods A total of 3888 patients who received chemotherapy for MRGC between January 2000 and December 2011 were analyzed via a prospectively collected registry. The analysis focused on the comparison among three periods: 2000-2003 (period 1), 2004-2007 (period 2) and 2008-2011 (period 3).

Results There were 880 patients (23\%) in period 1, 1573 $(40 \%)$ in period 2 and 1435 (37\%) in period 3. The most commonly used first-line chemotherapy regimen was fluoropyrimidine with/without platinum (72\%) for all periods. The use of second- and third-line chemotherapy was slightly but significantly more common in the two recent periods: 46 and $19 \%$ in period 1, 54 and $26 \%$ in period 2, and 53 and $27 \%$ in period 3, respectively. Overall, 3494 patients $(89.9 \%)$ died with a median overall survival (OS) of 10.6 months (95\% CI 10.2-11.0). The OS was
\end{abstract}

D. H. Koo - M.-H. Ryu - B.-Y. Ryoo - J. Seo - H.-M. Chang ·

J.-L. Lee · S.-S. Lee · T. W. Kim · Y.-K. Kang ( $\square)$

Department of Oncology, Asan Medical Center, University of

Ulsan College of Medicine, 88, Olympic-ro 43-gil, Songpa-gu,

Seoul 138-736, Korea

e-mail: ykkang@amc.seoul.kr

D. H. Koo

Division of Hematology/Oncology, Department of Internal Medicine, Kangbuk Samsung Medical Center, Sungkyunkwan University School of Medicine, Seoul, Korea

M.-Y. Lee

Division of Biostatistics, Department of Medical Information, Kangbuk Samsung Medical Center, Seoul, Korea statistically significantly improved over the study period: 9.6 months (95\% CI 9.0-10.2) in period 1, 10.3 months (95\% CI 9.8-10.9) in period 2 and 11.7 months (95\% CI $11.0-12.4$ ) in period 3 ( $p$ for trend $<0.001$ ). Multivariate analysis including eight prognostic factors (performance, gastrectomy, peritoneal/bone/lung metastasis, abnormal alkaline phosphatase/albumin/total bilirubin) showed that the more recent treatment period was an independent favorable prognostic factor for OS $(p<0.001)$.

Conclusion The OS of patients who receive chemotherapy for MRGC has been shown to improve over time.

Keywords Stomach neoplasm - Prognosis - Treatment outcome Period

\section{Introduction}

Gastric cancer is the leading cause of cancer death worldwide. The median survival for patients diagnosed at an advanced stage is $<1$ year [1, 2]. In the early 1990s, randomized clinical trials showed that chemotherapy added to best supportive care improved median survival time from 3-5 to 8-12 months compared with best supportive care alone in patients with advanced gastric cancer [3-5]. Two recent phase III studies of second-line chemotherapy for advanced gastric cancer also showed a survival benefit of 4-5 months with chemotherapy plus best supportive care, which was increased from 2 to 3 months with best supportive care alone $[6,7]$.

Consensus has been achieved regarding the role of adjuvant chemotherapy in patients who underwent curative surgery with D2 dissection for locally advanced gastric cancer $[8,9]$. A targeted agent such as trastuzumab showed a median survival time of $>1$ year in advanced gastric 
cancer and is now a standard therapy in patients with HER2-positive gastric cancer [10]. The efficacy of systemic chemotherapy for gastric cancer has been improving.

Several studies have reported the outcomes of gastric cancer treatment in different time periods. Although some epidemiological and clinical studies have demonstrated an improving prognosis in recent years [11-13], little is known about the treatment outcome of patients receiving chemotherapy for advanced gastric cancer according to time period.

Therefore, this retrospective study evaluates changes in clinical features and treatment outcomes of patients with metastatic or recurrent gastric cancer (MRGC) treated at a single institution.

\section{Materials and methods}

Patients and data collection

We examined the Asan Medical Center Stomach Cancer Registry to identify all patients who were treated for advanced gastric cancer at the Asan Medical Center (Seoul, Korea) between January 2000 and December 2011. We identified a total of 4288 patients who had received firstline palliative chemotherapy for metastatic (initially presenting with metastatic disease) or recurrent (recurrence of either local or distant tumors, or both, after a previous curative gastrectomy) gastric cancer (MRGC). Patients over 18 years of age with a histologically confirmed adenocarcinoma of the stomach who received at least one cycle of chemotherapy and who had no history of other malignancies were included. Patients with locally advanced disease or who underwent R1 resection for microscopic residual tumors just before chemotherapy were excluded. The excluded patients were regarded as having a lower tumor burden than patients with MRGC. Of the 4288 patients screened, 3888 fulfilled the inclusion criteria. Patients' medical records, stored in a prospectively collected registry, were reviewed for information regarding demographic data, tumor characteristics, treatment types, treatment responses and survival. The last update for each patient was obtained in December 2012, until the date of death or closing of follow-up. The analysis focused on three intervals: 2000-2003 (period 1), 2004-2007 (period 2) and 2008-2011 (period 3). The study protocol was approved by the Institutional Review Board of the Asan Medical Center.

In addition, patients were grouped by our prognostic model for MRGC [14]. This model used a scoring system consisting of eight prognostic factors [Eastern Cooperative Oncology Group (ECOG) performance score (PS) $\geq 2$ or bone metastasis (2 points each); no gastrectomy, peritoneal metastasis, lung metastasis, alkaline phosphatase $>120$ IU/ 1 , albumin $<3.3 \mathrm{~g} / \mathrm{dl}$ or total bilirubin $>1.2 \mathrm{mg} / \mathrm{dl}$ ( 1 point each)], with patients divided into good ( $0-1$ points), moderate (2-3) and poor $(\geq 4)$ risk groups.

Statistical analysis

Differences in patient and tumor characteristics during the three periods were analyzed using the Chi-square test or one-way ANOVA. Overall survival (OS) was measured from the starting date of first-line chemotherapy until death from any cause. Progression-free survival (PFS) was measured from the starting date of first-line chemotherapy until tumor progression or death from any cause. Survival rates were estimated using the Kaplan-Meier method and compared using the log-rank test. Prognostic factors were analyzed using Cox proportional hazard regression models. A two-sided $p$ value $<0.05$ was considered significant, and $95 \%$ confidence intervals (CIs) were calculated. All statistical analyses were performed using the SPSS 18.0 software package (IBM SPSS Statistics, USA).

\section{Results}

Between 2000 and 2011, a total of 3888 patients received palliative chemotherapy as first-line treatment for MRGC: $880(22.6 \%)$ in period $1,1573(40.5 \%)$ in period 2 and $1435(36.9 \%)$ in period 3 . The median age was 57 years (range 19-91 years), and there were 1415 patients (36.4\%) with recurrent gastric cancer: $303(34.4 \%)$ in period 1, 600 $(38.1 \%)$ in period 2 and $512(35.7 \%)$ in period 3. A comparison of clinical characteristics among the three periods is shown in Table 1. Slight but significant changes were observed in terms of age, ECOG PS status, number of organ metastases and peritoneal seeding in period $3 \mathrm{com}-$ pared with earlier periods. In particular, the analysis demonstrated a significant increase in the proportion of patients in the poor risk group (score 4 or more, $p$ for trend $<0.001$ ). There were no significant changes in trends of sex, prior gastrectomy, hepatic metastasis, or lung and bone metastasis.

The analysis of chemotherapy data in the three periods is summarized in Table 2. The most commonly used firstline cytotoxic chemotherapy agent was fluoropyrimidine with/without platinum: $579(65.8 \%)$ in period 1, 1083 $(68.8 \%)$ in period 2 and $1153(80.3 \%)$ in period 3. The most commonly used first-line chemotherapy regimen was fluoropyrimidine with/without platinum (60-75\%) [1523], and taxane-based chemotherapy was most commonly used as second line $(50 \%)[24,25]$. A triplet regimen including taxane, fluoropyrimidine and platinum was administered to $\sim 8 \%$ of patients over all periods [26-28]. 
Table 1 Patient characteristics by treatment period

\begin{tabular}{|c|c|c|c|c|}
\hline & $\begin{array}{l}2000-2003(N=880,22.6 \%) \\
N(\%)\end{array}$ & $\begin{array}{l}2004-2007(N=1573,40.5 \%) \\
N(\%)\end{array}$ & $\begin{array}{l}2008-2011(N=1435,36.9 \%) \\
N(\%)\end{array}$ & $p$ for trend \\
\hline \multicolumn{5}{|l|}{ Sex } \\
\hline Male & $583(66.3 \%)$ & $1023(65.0 \%)$ & $952(66.3 \%)$ & 0.864 \\
\hline \multicolumn{5}{|l|}{ Age } \\
\hline Median, range & $56(19-82)$ & $57(20-88)$ & $57(20-91)$ & 0.007 \\
\hline$\geq 65$ years & $196(22.3 \%)$ & $427(27.1 \%)$ & $421(29.3 \%)$ & $<0.001$ \\
\hline \multicolumn{5}{|l|}{ ECOG PS } \\
\hline $0 / 1$ & $834(95.1 \%)$ & $1377(88.3 \%)$ & $1071(85.4 \%)$ & $<0.001$ \\
\hline $2 / 3$ & $43(4.9 \%)$ & $182(11.7 \%)$ & $183(14.6 \%)$ & \\
\hline \multicolumn{5}{|l|}{ Gastrectomy } \\
\hline Done & $416(47.3 \%)$ & $743(47.2 \%)$ & $625(43.6 \%)$ & 0.053 \\
\hline \multicolumn{5}{|l|}{ Status } \\
\hline Recurrent & $303(34.4 \%)$ & $600(38.1 \%)$ & $512(35.7 \%)$ & 0.758 \\
\hline Metastatic & $577(65.6 \%)$ & $973(61.9 \%)$ & $923(64.3 \%)$ & \\
\hline \multicolumn{5}{|l|}{ Histology } \\
\hline $\mathrm{WD}+\mathrm{MD}$ & $213(24.2 \%)$ & $427(27.1 \%)$ & $400(27.9 \%)$ & 0.012 \\
\hline PD + Undiff & $581(66.0 \%)$ & $933(59.3 \%)$ & $922(64.3 \%)$ & \\
\hline Unclassified & $86(9.8 \%)$ & $213(13.5 \%)$ & $113(7.9 \%)$ & \\
\hline \multicolumn{5}{|l|}{ No. of metastasis } \\
\hline 2 or more organs & $236(26.8 \%)$ & $505(32.1 \%)$ & $559(39.0 \%)$ & $<0.001$ \\
\hline \multicolumn{5}{|l|}{ Peritoneal } \\
\hline Metastasis & $384(43.6 \%)$ & $689(43.8 \%)$ & $750(52.7 \%)$ & $<0.001$ \\
\hline \multicolumn{5}{|l|}{ Liver } \\
\hline Metastasis & $226(25.7 \%)$ & $426(27.1 \%)$ & $357(25.1 \%)$ & 0.625 \\
\hline \multicolumn{5}{|l|}{ Lung } \\
\hline Metastasis & $33(3.8 \%)$ & $81(5.2 \%)$ & $68(4.8 \%)$ & 0.333 \\
\hline \multicolumn{5}{|l|}{ Bone } \\
\hline Metastasis & $50(5.7 \%)$ & $111(7.1 \%)$ & $105(7.4 \%)$ & 0.135 \\
\hline \multicolumn{5}{|l|}{ ALP } \\
\hline$>120 \mathrm{IU} / 1$ & $260(29.6 \%)$ & $300(19.1 \%)$ & $288(20.2 \%)$ & $<0.001$ \\
\hline \multicolumn{5}{|l|}{ Albumin } \\
\hline$<3.3 \mathrm{~g} / \mathrm{dl}$ & $218(24.8 \%)$ & $469(29.9 \%)$ & $373(26.1 \%)$ & 0.816 \\
\hline \multicolumn{5}{|l|}{ Total bilirubin } \\
\hline$>1.2 \mathrm{mg} / \mathrm{dl}$ & $59(6.7 \%)$ & $114(7.3 \%)$ & $101(7.1 \%)$ & 0.816 \\
\hline \multicolumn{5}{|l|}{ Prognostic score } \\
\hline $0-1$ (good) & $382(44.0 \%)$ & $684(44.5 \%)$ & $520(41.9 \%)$ & $<0.001$ \\
\hline 2-3 (moderate) & $419(48.2 \%)$ & $625(40.6 \%)$ & $513(41.3 \%)$ & \\
\hline 4 or more (poor) & $68(7.8 \%)$ & $229(14.9 \%)$ & $208(16.8 \%)$ & \\
\hline
\end{tabular}

ECOG PS Eastern Cooperative Oncology Group Performance Status, $W D$ well differentiated, $M D$ moderately differentiated, $P D$ poorly differentiated, Undiff undifferentiated, ALP alkaline phosphatase

Targeted therapies such as trastuzumab [10], cetuximab [29, 30], sorafenib [31], bevacizumab [32], vorinostat [33] and everolimus [34] were administered to a total of 262 patients $(6.7 \%)$ as first-line treatment, and these were also the most commonly used in period 3 . Use of oral fluoropyrimidine increased significantly since period 2 ( $p$ for trend <0.001) [15-18, 22, 23, 35]. Second-line chemotherapy was administered to 2018 patients (51.9\%), and third-line chemotherapy was administered to 967 patients (24.9\%). The proportion of patients who received secondand third-line treatment increased slightly but significantly in the recent two periods compared to period 1 ( $p$ for trend $<0.002$; <0.001, respectively) [24, 25, 36, 37].

Overall, 3494 patients (89.9\%) died, with a median OS of 10.6 months (95\% CI 10.2-11.0). The median followup time for living patients was 25.2 months [interquartile 
Table 2 Treatment characteristics by treatment period

\begin{tabular}{|c|c|c|c|c|}
\hline & $2000-2003(N=880,22.6 \%)$ & 2004-2007 $(N=1573,40.5 \%)$ & 2008-2011 $(N=1435,36.9 \%)$ & $p$ for trend \\
\hline \multicolumn{5}{|l|}{ First-line chemotherapy } \\
\hline Single $^{\mathrm{a}}$ & $103(11.7)$ & $450(28.6)$ & $150(10.5)$ & \multirow[t]{5}{*}{0.145} \\
\hline Doublet $^{\mathrm{b}}$ & $698(79.3)$ & $934(59.4)$ & $1001(69.7)$ & \\
\hline Triplet (cytotoxic) ${ }^{\mathrm{c}}$ & $79(9.0)$ & $124(7.9)$ & $87(6.1)$ & \\
\hline Triplet (targeted) ${ }^{\mathrm{c}}$ & $0(0.0)$ & $55(3.5)$ & $149(10.4)$ & \\
\hline Triplet (trastuzumab) ${ }^{\mathrm{e}}$ & $0(0.0)$ & $10(0.6)$ & $48(3.3)$ & \\
\hline \multicolumn{5}{|l|}{ Oral/IV fluoropyrimidine } \\
\hline Oral & $436(56.5)$ & $1195(93.7)$ & $1096(83.9)$ & $<0.001$ \\
\hline \multicolumn{5}{|l|}{ Platinum $^{\mathrm{f}}$} \\
\hline Oxaliplatin & $3(0.3)$ & $218(13.9)$ & $281(19.6)$ & $<0.001$ \\
\hline \multicolumn{5}{|l|}{ Study/practice } \\
\hline Study & $264(30.0)$ & $323(20.5)$ & $407(28.4)$ & 0.957 \\
\hline \multicolumn{5}{|l|}{ Second-line } \\
\hline Received & $405(46.0)$ & $846(53.8)$ & $767(53.4)$ & 0.002 \\
\hline \multicolumn{5}{|l|}{ Third-line } \\
\hline Received & $165(18.8)$ & $416(26.4)$ & $386(26.9)$ & $<0.001$ \\
\hline \multicolumn{5}{|c|}{ 2/3rd-line targeted therapy } \\
\hline Received & $24(2.7)$ & $43(2.7)$ & $114(15.9)$ & $<0.001$ \\
\hline \multicolumn{5}{|c|}{ a Single: fluoropyrimidine $(\mathrm{F})$, taxane $(\mathrm{T})$ or irinotecan $(\mathrm{I})$} \\
\hline \multicolumn{5}{|c|}{ b Doublet: F/platinum (P), T/P, F/I, F/T, T/I, anthracycline (A)/P, A/F } \\
\hline \multicolumn{5}{|c|}{ c Triplet (cytotoxic): F/P/T } \\
\hline \multicolumn{5}{|c|}{${ }^{\mathrm{d}}$ Triplet (targeted): doublet with targeted agents excluding trastuzumab } \\
\hline \multicolumn{5}{|c|}{ e Triplet (trastuzumab): doublet/trastuzumab } \\
\hline f Platinum: in doublet $\mathrm{o}$ & riplet chemotherapy & & & \\
\hline
\end{tabular}

range (IQR) 13.7-55.7 months). The OS showed statistically significant improvement over the study period: 9.6 months (95\% CI 9.0-10.2) in period 1, 10.3 months (95\% CI 9.8-10.9) in period 2 and 11.7 months (95\% CI $11.0-12.4$ ) in period 3 ( $p$ for trend $<0.001$, Fig. 1a). The median PFS was 5.6 months (95\% CI 5.4-5.8), which was similar over the time periods: 5.7 months $(95 \%$ CI 5.2-6.1) in period 1, 5.4 months (95\% CI 5.0-5.8) in period 2 and 5.8 months (95\% CI 5.5-6.2) in period 3 ( $p$ for trend $=0.264$, Fig. $1 b$ ). However, the comparison of period 1 and 2 (5.4 months, $95 \%$ CI 5.1-5.7) with the period 3 (5.8 months) was statistically significantly different $(p=0.047)$.

According to our previous prognostic model using eight prognostic factors (mentioned previously) [14], the patients were grouped into three groups. In the good risk group, the OS showed statistically significant improvement over the study period: 12.3 months (95\% CI 11.0-13.6) in period 1 , 13.0 months $(95 \%$ CI 11.8-14.1) in period 2 and 15.8 months (95 \% CI 14.9-16.7 months) in period 3 ( $p$ for trend $=0.002$, Fig. $2 \mathrm{a}$ ). In the moderate risk group, the OS also showed statistically significant improvement over the period: 8.7 months (95\% CI 8.0-9.4) in period 1,
10.1 months (95\% CI 9.2-10.9) in period 2 and 10.7 months (95\% CI 9.6-11.7) in period 3 ( $p$ for trend $<0.001$, Fig. 2b). In the poor risk group, however, the OS showed no significant difference over the period: 5.6 months (95\% CI 4.8-6.3) in period 1, 5.5 months (95\% CI 4.7-6.3) in period 2 and 6.1 months (95\% CI 5.3-6.9) in period 3 ( $p$ for trend $=0.458$, Fig. $2 \mathrm{c}$ ). In addition, among the 58 patients who had received doublet chemotherapy with trastuzumab as first-line treatment, 41 patients $(70.7 \%)$ died. With a median follow-up duration of 25.6 months (range 21.0-61.8), the median OS and PFS were 21.1 months (95\% CI 15.0-27.2) and 10.9 months (95\% CI 8.6-13.1), respectively (Fig. 3a).

Multivariate analysis for factors influencing OS was carried out including eight prognostic factors and time period (Table 3). Recent time period was confirmed as an independently favorable prognostic factor for OS $(p<0.001)$. The HR for OS in period 2 compared with period 1 was 0.922 (95\% CI 0.86-1.01) and in period 3 was 0.804 (95\% CI 0.73-0.88). As patients in these three groups were treated at different times, the assumption of proportionality of the risk during the time after first-line chemotherapy was verified by the log-minus-log plot (LML 

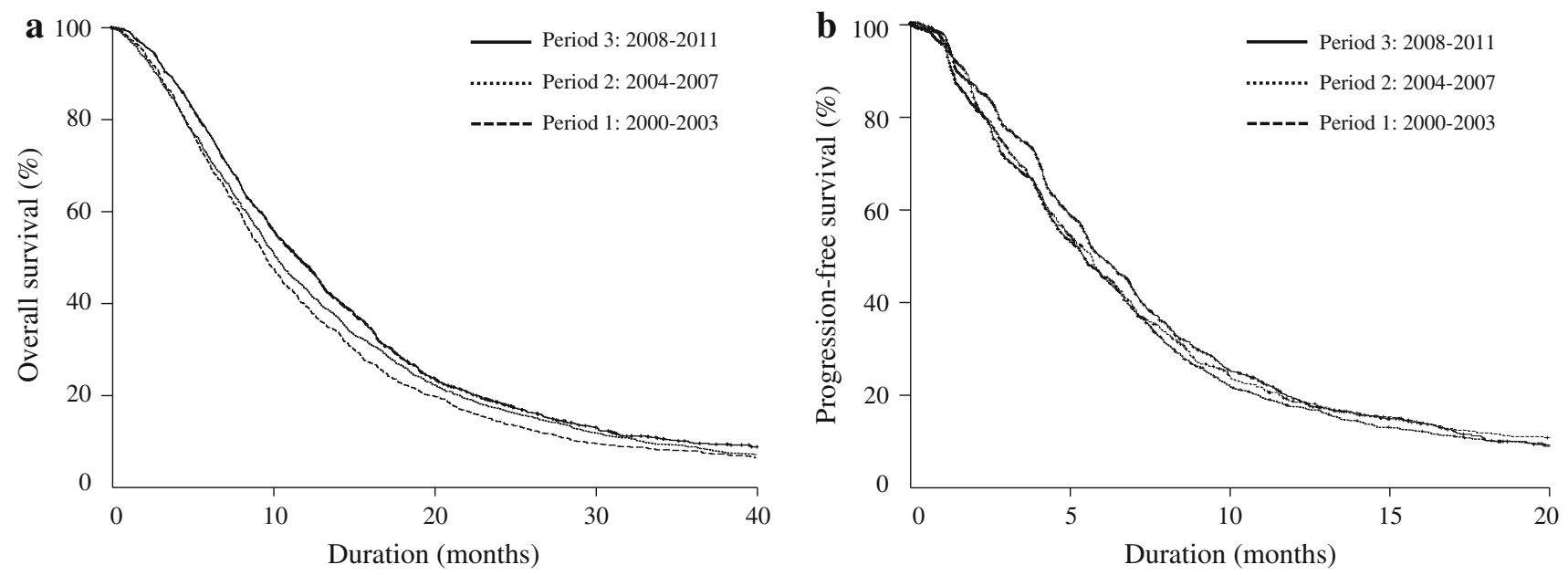

Fig. 1 Overall survival (a) and progression-free survival (b) curves according to treatment period
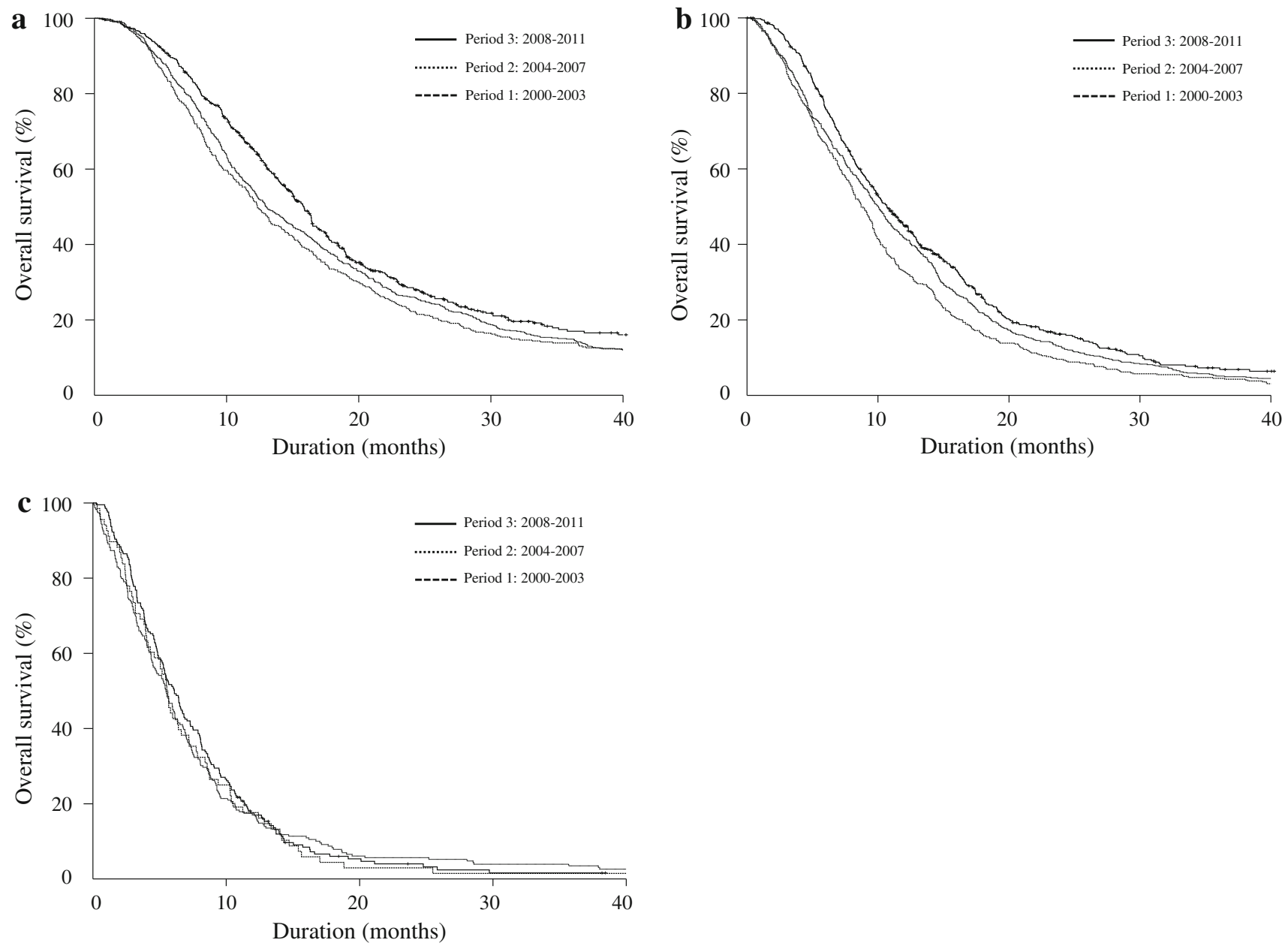

Fig. 2 Overall survival curves according to risk group: a good risk, $\mathbf{b}$ moderate risk and $\mathbf{c}$ poor risk group 


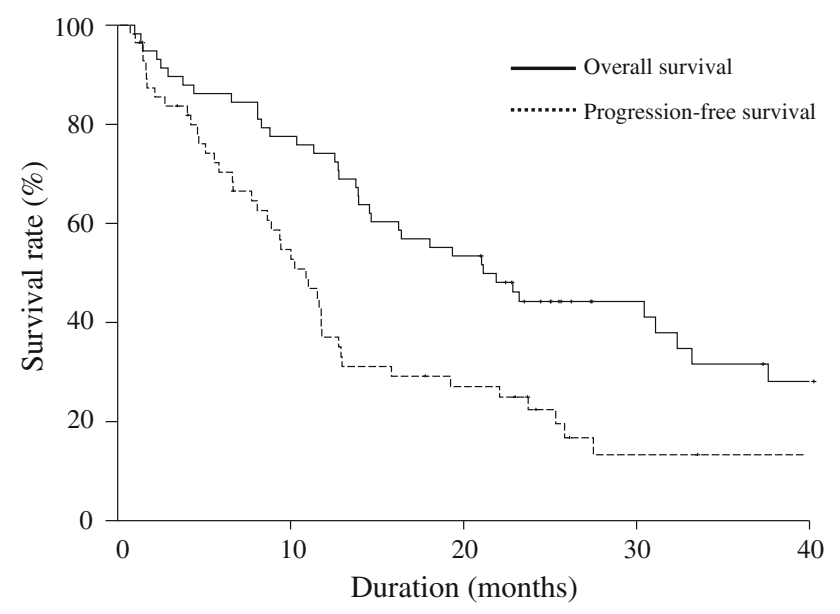

Fig. 3 Overall survival and progression-free survival curves of patients who had received doublet chemotherapy with trastuzumab as first-line treatment

Table 3 Multivariate analysis of factors associated with overall survival

\begin{tabular}{lllr}
\hline & Hazard ratio & $95 \%$ CI & $p$ value \\
\hline ECOG PS 2/3 & 1.592 & $1.420-1.785$ & $<0.001$ \\
No gastrectomy & 1.286 & $1.198-1.382$ & $<0.001$ \\
Peritoneal metastasis & 1.269 & $1.182-1.362$ & $<0.001$ \\
Bone metastasis & 1.721 & $1.494-1.982$ & $<0.001$ \\
Lung metastasis & 1.420 & $1.209-1.669$ & $<0.001$ \\
Elevated ALP & 1.361 & $1.243-1.490$ & $<0.001$ \\
Decreased albumin & 1.324 & $1.221-1.436$ & $<0.001$ \\
Elevated T-bilirubin & 1.139 & $0.992-1.309$ & 0.065 \\
Period 1 (2000-2003) & Reference & - & $<0.001$ \\
Period 2 (2004-2007) & 0.922 & $0.846-1.006$ & 0.067 \\
Period 3 (2008-2011) & 0.804 & $0.732-0.884$ & $<0.001$ \\
\hline
\end{tabular}

$H R$ hazard ratio, ECOG PS Eastern Cooperative Oncology Group Performance Status, ALP alkaline phosphatase, T-bilirubin total bilirubin

plot) against time after chemotherapy. The parallelism of the three curves confirmed the assumption, indicating that the inclusion of the variable (time period) in the Cox model was correct, and its statistical significance was verified.

\section{Discussion}

This study analyzed the changes in clinical features and treatment outcomes of patients with MRGC in a single institution during the past 12 years. In more recent periods, trends included increasing patient age, declining ECOG PS and increasing numbers of organ metastases.
The proportions of sex, gastrectomy status, histology differentiation, and liver or bone metastasis remained constant. It is particularly notable that OS improved over time: median OS increased about 2 months. This finding was confirmed as an independent favorable prognostic factor after multivariate analysis adjusted for major prognostic factors.

There were several possible explanations for improved treatment outcome over these periods. The proportion of patients who received sequential second- or third-line chemotherapy increased [36-38]. Although the role of salvage chemotherapy was not proven in advanced gastric cancer until the late 2000s, two recent phase III trials demonstrated the benefit of the second-line chemotherapy for the improvement of survival outcome in patients with advanced gastric cancer [6,7]. Similar outcomes in terms of PFS for first-line chemotherapy over the periods and the OS improvement in the specific group of patients, particularly in the good and moderate risk groups, also support the association between use of sequential chemotherapies and OS improvement.

Although the most commonly used first-line chemotherapy regimen was fluoropyrimidine with/without platinum $(60-75 \%)$ [15-23], some feasible patients, who had good performance or low tumor burden such as isolated para-aortic lymph node metastasis, were treated with a triplet regimen including taxane, fluoropyrimidine and platinum [26-28]. Those were about $8 \%$ of all patients (290 patients) over all the periods, and their survival outcome of 7.8 months in PFS (95\% CI 7.0-8.6 months) and 14.0 months in OS (95\% CI 12.6-15.4 months) was not significantly different among the three periods $(p=0.485$, $p=0.512$, respectively). Additionally, the trends, which included increasing patient age, numbers of metastases and poor risk groups, could suggest that the PFS was also improved in patients with the same condition or tumor burden although the PFS was not significantly different over the periods.

The recently diagnosed patients with advanced gastric cancer tended to have a better prognostic indication such as a lower number of metastases or good PS due to early detection. However, we indicate in Table 1 that a larger number of recent patients had a higher prognostic score. There are several possible explanations for this. First, a more aggressive palliative treatment strategy may have been in use for more recent patients, and older patients or those with a poorer performance status agreed to receive palliative chemotherapy. Second, patients showing indicators of a poor prognosis, including a heavy tumor burden, tend to be referred from local hospitals for palliative chemotherapy. These two aspects may have contributed to this observed trend of an increased proportion of patients with higher prognostic scores in recent periods. 
There were substantial changes to the cytotoxic agents used in the doublet chemotherapy, such as oral fluoropyrimidine and oxaliplatin. Although some studies have suggested some survival benefit of oral fluoropyrimidine and oxaliplatin over IV fluoropyrimidine and cisplatin, respectively, [39, 40], we could not draw any conclusions because the proportion of patients who received sequential second- or third-line chemotherapy was also significantly increased in these periods.

Since trastuzumab became a standard therapy for patients with HER2-positive gastric tumors, the role of targeted agents has been actively explored [10]. The use of trastuzumab with doublet chemotherapy has increased in the recent period, and the PFS and OS have been improved compared with all patients in this analysis. As an increasing number of targeted agents have been used in recent clinical trials [41], ramucirumab, a new monoclonal antibody VEGFR-2 antagonist, has shown survival benefits after first-line chemotherapy [42]. Further active investigations with target agents are needed based on biomarkerdriven clinical trials [34].

In summary, this analysis showed the potential changes in clinical features and treatment outcomes in patients with MRGC over the past 12 years. The OS of patients was shown to improve over time with the advances in chemotherapy and supportive care.

\section{References}

1. Hohenberger P, Gretschel S. Gastric cancer. Lancet. 2003;362:305-15.

2. Wagner AD, Unverzagt S, Grothe W, Kleber G, Grothey A, Haerting J, Fleig WE. Chemotherapy for advanced gastric cancer. Cochrane Database Syst Rev. 2010;(3), Art no. CD004064. doi:10.1002/14651858.CD004064.pub3.

3. Murad AM, Santiago FF, Petroianu A, Rocha PR, Rodrigues MA, Rausch M. Modified therapy with 5-fluorouracil, doxorubicin, and methotrexate in advanced gastric cancer. Cancer. 1993;72:37-41.

4. Pyrhonen S, Kuitunen T, Nyandoto P, Kouri M. Randomised comparison of fluorouracil, epidoxorubicin and methotrexate (FEMTX) plus supportive care with supportive care alone in patients with non-resectable gastric cancer. $\mathrm{Br} \mathrm{J}$ Cancer. 1995;71:587-91.

5. Glimelius B, Ekström K, Hoffman K, Graf W, Sjödén P-O, Haglund U, et al. Randomized comparison between chemotherapy plus best supportive care with best supportive care in advanced gastric cancer. Ann Oncol. 1997;8:163-8.

6. Thuss-Patience PC, Kretzschmar A, Bichev D, Deist T, Hinke A, Breithaupt K, et al. Survival advantage for irinotecan versus best supportive care as second-line chemotherapy in gastric cancer-a randomised phase III study of the Arbeitsgemeinschaft Internistische Onkologie (AIO). Eur J Cancer. 2011;47:2306-14.

7. Kang JH, Lee SI, Lim DH, Park KW, Oh SY, Kwon HC, et al. Salvage chemotherapy for pretreated gastric cancer: a randomized phase III trial comparing chemotherapy plus best supportive care with best supportive care alone. J Clin Oncol. 2012;30:1513-8.

8. Sakuramoto S, Sasako M, Yamaguchi T, Kinoshita T, Fujii M, Nashimoto A, et al. Adjuvant chemotherapy for gastric cancer with S-1, an oral fluoropyrimidine. $\mathrm{N}$ Engl $\mathrm{J}$ Med. 2007;357:1810-20.

9. Bang YJ, Kim YW, Yang HK, Chung HC, Park YK, Lee KH, et al. Adjuvant capecitabine and oxaliplatin for gastric cancer after D2 gastrectomy (CLASSIC): a phase 3 open-label, randomised controlled trial. Lancet. 2012;379:315-21.

10. Bang YJ, Van Cutsem E, Feyereislova A, Chung HC, Shen L, Sawaki A, et al. Trastuzumab in combination with chemotherapy versus chemotherapy alone for treatment of HER2-positive advanced gastric or gastro-oesophageal junction cancer (ToGA): a phase 3, open-label, randomised controlled trial. Lancet. 2010;376:687-97.

11. Jung KW, Won YJ, Kong HJ, Oh CM, Seo HG, Lee JS. Cancer statistics in Korea: incidence, mortality, survival and prevalence in 2010. Cancer Res Treat. 2013;45:1-14.

12. Hansson LE, Sparen P, Nyren O. Survival in stomach cancer is improving: results of a nationwide population-based Swedish study. Ann Surg. 1999;230:162-9.

13. Hyung WJ, Kim SS, Choi WH, Cheong JH, Choi SH, Kim CB, et al. Changes in treatment outcomes of gastric cancer surgery over 45 years at a single institution. Yonsei Med J. 2008;49:409-15.

14. Koo DH, Ryoo BY, Kim HJ, Ryu MH, Lee SS, Moon JH, et al. A prognostic model in patients who receive chemotherapy for metastatic or recurrent gastric cancer: validation and comparison with previous models. Cancer Chemother Pharmacol. 2011;68:913-21.

15. Kim TW, Kang YK, Ahn JH, Chang HM, Yook JH, Oh ST, et al. Phase II study of capecitabine plus cisplatin as first-line chemotherapy in advanced gastric cancer. Ann Oncol. 2002;13:1893-8.

16. Kang HJ, Chang HM, Kim TW, Ryu MH, Sohn HJ, Yook JH, et al. Phase II study of capecitabine and cisplatin as first-line combination therapy in patients with gastric cancer recurrent after fluoropyrimidine-based adjuvant chemotherapy. $\mathrm{Br} \mathrm{J}$ Cancer. 2005;92:246-51.

17. Lee SS, Lee JL, Ryu MH, Chang HM, Kim TW, Kang HJ, et al. Combination chemotherapy with capecitabine (X) and cisplatin (P) as first line treatment in advanced gastric cancer: experience of 223 patients with prognostic factor analysis. Jpn J Clin Oncol. 2007;37:30-7.

18. Kang YK, Kang WK, Shin DB, Chen J, Xiong J, Wang J, et al. Capecitabine/cisplatin versus 5 -fluorouracil/cisplatin as first-line therapy in patients with advanced gastric cancer: a randomised phase III noninferiority trial. Ann Oncol. 2009;20:666-73.

19. Koo DH, Ryu MH, Ryoo BY, Lee SS, Moon JH, Chang HM, et al. Three-week combination chemotherapy with S-1 and cisplatin as first-line treatment in patients with advanced gastric cancer: a retrospective study with 159 patients. Gastric Cancer. 2012;15:305-12.

20. Park I, Lee JL, Ryu MH, Chang HM, Kim TW, Sym SJ, et al. Phase I/II and pharmacokinetic study of S-1 and oxaliplatin in previously untreated advanced gastric cancer. Cancer Chemother Pharmacol. 2010;65:473-80.

21. Lee JL, Kang HJ, Kang YK, Ryu MH, Chang HM, Kim TW, et al. Phase I/II study of 3-week combination of S-1 and cisplatin chemotherapy for metastatic or recurrent gastric cancer. Cancer Chemother Pharmacol. 2008;61:837-45.

22. Lee JL, Kang YK, Kang HJ, Lee KH, Zang DY, Ryoo BY, et al. A randomised multicentre phase II trial of capecitabine vs S-1 as first-line treatment in elderly patients with metastatic or recurrent unresectable gastric cancer. Br J Cancer. 2008;99:584-90.

23. Park YH, Lee JL, Ryoo BY, Ryu MH, Yang SH, Kim BS, et al. Capecitabine in combination with oxaliplatin (XELOX) as a first- 
line therapy for advanced gastric cancer. Cancer Chemother Pharmacol. 2008;61:623-9.

24. Lee JL, Ryu MH, Chang HM, Kim TW, Yook JH, Oh ST, et al. A phase II study of docetaxel as salvage chemotherapy in advanced gastric cancer after failure of fluoropyrimidine and platinum combination chemotherapy. Cancer Chemother Pharmacol. 2008;61:631-7.

25. Jo JC, Lee JL, Ryu MH, Sym SJ, Lee SS, Chang HM, et al. Docetaxel monotherapy as a second-line treatment after failure of fluoropyrimidine and platinum in advanced gastric cancer: experience of 154 patients with prognostic factor analysis. Jpn J Clin Oncol. 2007;37:936-41.

26. Kang YK, Ryu MH, Yoo C, Chang HM, Yook JH, Oh ST, et al. Phase I/II study of a combination of docetaxel, capecitabine, and cisplatin (DXP) as first-line chemotherapy in patients with advanced gastric cancer. Cancer Chemother Pharmacol. 2011;67:1435-43.

27. Sym SJ, Chang HM, Ryu MH, Lee JL, Kim TW, Yook JH, et al. Neoadjuvant docetaxel, capecitabine and cisplatin (DXP) in patients with unresectable locally advanced or metastatic gastric cancer. Ann Surg Oncol. 2010;17:1024-32.

28. Sym S, Ryu M-H, Kang H, Lee S, Chang H-M, Lee J, et al. Phase I study of 3-weekly docetaxel, capecitabine and oxaliplatin combination chemotherapy in patients with previously untreated advanced gastric cancer. Cancer Chemother Pharmacol. 2010;66:373-80.

29. Kim C, Lee JL, Ryu MH, Chang HM, Kim TW, Lim HY, et al. A prospective phase II study of cetuximab in combination with XELOX (capecitabine and oxaliplatin) in patients with metastatic and/or recurrent advanced gastric cancer. Invest New Drugs. 2011;29:366-73.

30. Lordick F, Kang YK, Chung HC, Salman P, Oh SC, Bodoky G, et al. Capecitabine and cisplatin with or without cetuximab for patients with previously untreated advanced gastric cancer (EXPAND): a randomised, open-label phase 3 trial. Lancet Oncol. 2013;14:490-9.

31. Kim C, Lee JL, Choi YH, Kang BW, Ryu MH, Chang HM, et al. Phase I dose-finding study of sorafenib in combination with capecitabine and cisplatin as a first-line treatment in patients with advanced gastric cancer. Invest New Drugs. 2012;30:306-15.

32. Ohtsu A, Shah MA, Van Cutsem E, Rha SY, Sawaki A, Park SR, et al. Bevacizumab in combination with chemotherapy as firstline therapy in advanced gastric cancer: a randomized, doubleblind, placebo-controlled phase III study. J Clin Oncol. 2011;29:3968-76.

33. Yoo C, Ryu MH, Na YS, Ryoo BY, Lee CW, Maeng J, et al. Phase I and pharmacodynamic study of vorinostat combined with capecitabine and cisplatin as first-line chemotherapy in advanced gastric cancer. Invest New Drugs. 2014;32(2):271-8.

34. Yoon DH, Ryu MH, Park YS, Lee HJ, Lee C, Ryoo BY, et al. Phase II study of everolimus with biomarker exploration in patients with advanced gastric cancer refractory to chemotherapy including fluoropyrimidine and platinum. $\mathrm{Br} \mathrm{J}$ Cancer. 2012;106:1039-44.

35. Kang HJ, Chang HM, Kim TW, Ryu MH, Sohn HJ, Yook JH, et al. A phase II study of paclitaxel and capecitabine as a first-line combination chemotherapy for advanced gastric cancer. $\mathrm{Br} \mathrm{J}$ Cancer. 2008;98:316-22.

36. Sym SJ, Ryu MH, Lee JL, Chang HM, Kim TW, Lee SS, et al. Salvage chemotherapy with biweekly irinotecan, plus 5-fluorouracil and leucovorin in patients with advanced gastric cancer previously treated with fluoropyrimidine, platinum, and taxane. Am J Clin Oncol. 2008;31:151-6.

37. Sym SJ, Chang HM, Kang HJ, Lee SS, Ryu MH, Lee JL, et al. A phase II study of irinotecan and docetaxel combination chemotherapy for patients with previously treated metastatic or recurrent advanced gastric cancer. Cancer Chemother Pharmacol. 2008;63:1-8.

38. Chang HM, Kim TW, Ryu BY, Choi SJ, Park YH, Lee JS, et al. Phase II study of paclitaxel and carboplatin in advanced gastric cancer previously treated with 5-fluorouracil and platinum. Jpn J Clin Oncol. 2005;35:251-5.

39. Okines AF, Norman AR, McCloud P, Kang YK, Cunningham D. Meta-analysis of the REAL-2 and ML17032 trials: evaluating capecitabine-based combination chemotherapy and infused 5-fluorouracil-based combination chemotherapy for the treatment of advanced oesophago-gastric cancer. Ann Oncol. 2009;20:1529-34.

40. Montagnani F, Turrisi G, Marinozzi C, Aliberti C, Fiorentini G. Effectiveness and safety of oxaliplatin compared to cisplatin for advanced, unresectable gastric cancer: a systematic review and meta-analysis. Gastric Cancer. 2011;14:50-5.

41. Kang YK, Muro K, Ryu MH, Yasui H, Nishina T, Ryoo BY, et al. A phase II trial of a selective c-Met inhibitor tivantinib (ARQ 197) monotherapy as a second- or third-line therapy in the patients with metastatic gastric cancer. Invest New Drugs. 2014;32(2):355-61.

42. Fuchs CS, Tomasek J, Yong CJ, Dumitru F, Passalacqua R, Goswami C, et al. Ramucirumab monotherapy for previously treated advanced gastric or gastro-oesophageal junction adenocarcinoma (REGARD): an international, randomised, multicentre, placebo-controlled, phase 3 trial. Lancet. 2014;383(9911):31-9. 